\title{
An alternative flow cytometry strategy for peripheral blood dendritic cell enumeration in the setting of repetitive GM-CSF dosing
}

\author{
Kehui Wang1, Kevin P Nishimoto², Rita S Mehta ${ }^{1}$ and Edward L Nelson*1,2,3
}

Address: ${ }^{1}$ Department of Medicine, Division of Hematology/Oncology, School of Medicine, University of California, Irvine, USA, ${ }^{2}$ Department of Molecular Biology \& Biochemistry, School of Biological Sciences, University of California, Irvine, USA and ${ }^{3}$ Center for Immunology, University of California, Irvine, USA

Email: Kehui Wang - kwang@uci.edu; Kevin P Nishimoto - nishimok@uci.edu; Rita S Mehta - rsmehta@uci.edu; Edward L Nelson* - enelson@uci.edu

* Corresponding author

Published: 24 April 2006

Journal of Translational Medicine2006, 4:18 doi:10.1/86/1479-5876-4-18
Received: 08 January 2006

Accepted: 24 April 2006

This article is available from: http://www.translational-medicine.com/content/4/I//8

(c) 2006Wang et al; licensee BioMed Central Ltd.

This is an Open Access article distributed under the terms of the Creative Commons Attribution License (http://creativecommons.org/licenses/by/2.0), which permits unrestricted use, distribution, and reproduction in any medium, provided the original work is properly cited.

\begin{abstract}
Background: Enumeration of circulating peripheral blood dendritic cells (DCs) is complicated by the absence of a unique cell surface marker expressed on all DC subsets and by the use of various biological adjuvants to modulate the DC compartment, including granulocyte macrophage colony stimulating factor (GM-CSF). Common methods employ a cocktail of antibodies, typically including anti-CDI4, to define a lineage negative, MHC class II positive, putative DC population. Reported flow cytometry protocols include highly variable gating strategies and DC identification criteria. Increasing appreciation of DC pleiomorphism, GM-CSF biology, and recognition of CDI4 expression in some DC subsets led us to consider an alternative lineage cocktail to improve identification of the circulating DC pool.

Methods: Standard whole blood staining with appropriate fluorochrome conjugated antibodies to MHC class II and either standard CDI4 containing, or an alternate CD66acde containing, lineage cocktail was performed on samples obtained from normal donors and breast cancer patients before and after administration of dose-dense, cytotoxic chemotherapy with daily GM-CSF hematopoetic growth factor support. Putative DCs were enumerated by standard flow cytometry. Data set differences were evaluated using two tailed Mann-Whitney or Wilcoxon signed rank tests. Cellular morphology was examined in cellsorted populations from post GM-CSF samples.

Results: Use of either antibody cocktail defined comparably sized lineage negative, MHC class II positive populations in normal donors and at baseline in cancer patients. However, selection of lineage negative subsets with increasing MHC class II expression levels yielded larger putative DC populations identified with the alternate cocktail. Both cocktails yielded highly reproducible data. Use of the alternate cocktail: I) yielded a putative DC population, post GM-CSF that was more homogenous and consistent with DCs, 2) resulted in less data variation across gating strategies, and 3) resulted in more uniform and concordant longitudinal data, consistent with established GM-CSF biological activity.

Conclusion: An alternative lineage negative cocktail substituting anti-CD66 antibody for anti-CDI4 is a viable option for enumerating the circulating DC population, potentially more accurately defining the circulating DC pool by including CDI4 positive immature DCs, and thus, may give more reliable data, particularly in the setting of sustained GM-CSF administration.
\end{abstract}




\section{Background}

The recognition of dendritic cells (DCs) as the most potent antigen-presenting and immunostimulatory cell [1] has led to their incorporation into various immunotherapeutic and immunomodulatory strategies and has prompted the development of flow cytometry strategies for monitoring DCs. Monitoring of longitudinal changes in human DC populations necessitates evaluation of peripheral blood circulating DCs, as repeated lymph node biopsies are impractical. This ability to accurately monitor potential modulations of DCs is challenged by DC phenotypic pleiomorphism. DCs can manifest several phenotypes, including immature and mature [1-4], myeloid or type 1 (DC1) and lymphoid or type 2 (DC2). However, as there is no one marker that uniquely identifies DCs, analysis of DC populations and their modulations must be carefully interpreted.

Granulocyte macrophage colony stimulating factor (GMCSF), a glycoprotein hematopoetic growth factor with diverse effects [5-12], Table 1, a known trophic factor for DCs, and one of the major biological adjuvants being employed to modulate DC numbers and activity, primarily targets myeloid DCs or the DC1 subset. The ability of GM-CSF to increase the bone marrow production of both granulocytes and monocytes is well documented, but it also has been consistently reported to activate various cell populations and induce MHC class II expression [13-25]. This raises concerns regarding the accuracy of flow cytometry evaluations of DCs in the peripheral blood compartment using classic lineage negative, MHC class II positive criteria, particularly in the setting of GM-CSF administration.

The cytometric evaluation of DCs is complicated because unlike other leukocytes, there is no single cell surface or cytoplasmic marker for all DC subsets $[2,3]$ and there is no consensus on the most appropriate flow cytometry protocol. Although several commercially available DCspecific antibodies have been used to select or enumerate DC subsets, each identifies only a limited subset of DCs. The most widely used criteria for defining circulating DCs is lineage negative (neither lymphocytes nor monocytes nor NK cells) and MHC class II positive. The classic lineage negative antibody cocktails incorporate antibodies to T lymphocytes (anti-CD3), B lymphocytes (anti CD19 and/or anti-CD20), NK cells (anti-CD16 and/or antiCD56) and monocytes (anti-CD14). However, low level CD14 expression by immature DCs and type 1 DC precursors (pDC1) [2] and the expression of CD16 by a subset of DCs $[3,39,40]$ can lead to the potential incorrect assignment of cells. Additionally, various disease states, recovery from myelosuppressive chemotherapy, and/or repetitive GM-CSF administration can increase the number of circulating MHC class II positive cells complicating the use of these cocktails [14,41-47] and imparting further error to the methodology. We postulated that an antibody cocktail that would identify granulocytes, NK cells, lymphocyte lineages, and activated monocytes in whole blood analyses would potentially provide a more accurate enumeration of circulating DCs. Members of the CD66 family, recognized by commercially available monoclonal antibodies, are widely expressed on granulocytes, NK cells, lymphocytes, and activated monocytes/macrophages [48$55]$ and provide candidate antibodies for a lineage negative cocktail that would permit more consistent identification of the circulating DC population, even in the setting of repeated administration of the biological adjuvant, GM-CSF.

\section{Methods \\ Blood samples}

All human blood samples were collected in accordance with IRB reviewed and approved research protocols. Anonymous normal donor samples from adult subjects, 23 to 55 years of age, were obtained through the normal blood donor program administered and run by the UCI GCRC. Subjects receiving dose-dense chemotherapy for a diagnosis of breast adenocarcinoma consisting of doxorubicin (Adriamycin) $60 \mathrm{mg} / \mathrm{m}^{2} \mathrm{~d} 1$ followed by cyclophosphamide (Cytoxan) $600 \mathrm{mg} / \mathrm{m}^{2} \mathrm{~d} 1$, administered in a 14 day cycle received 10 days of GM-CSF at the standard hematopoetic support dose of $250 \mathrm{ug} / \mathrm{m}^{2}$ administered by subcutaneous (SC) injection starting on day 3, under an IRB approved protocol. GM-CSF administration terminated $\geq 24$ hours before the next administration of cytotoxic drugs. Samples from these subjects constitute the "patient" cohort. Standard phlebotomy was performed using EDTA containing collection tubes prior to initiation of chemotherapy, "baseline" and after the 10 days of GMCSF.

Table I: Diverse biological activities of GM-CSF.

\footnotetext{
In vitro activation of macrophages, monocytes, and dendritic cells [26-30].

In vivo administration activates monocyte at low doses in clinical studies [31-33].

Increases antigen processing and presentation by Macrophages [34-36].

Enhanced in vitro tumoricidal activity of PBMC for human melanoma cells [26].

Induces macrophage production of an angiogenesis inhibitor [37, 38].
} 


\section{Whole blood staining}

Two hundred microliters of well-mixed whole blood was used for each analysis. All elements of the procedure were carried out at room temperature unless otherwise noted. Antibodies were added to these samples and incubated for 60 minutes in the dark, with frequent agitation. After the addition of red cell lysis media ACK (MP Biomedical, Irvine, CA) the mixture was incubated for an additional 15 minutes. Cells were collected by centrifugation at 1000 $\mathrm{RPM} \times 5$ minutes, the supernatant was discarded, and the cell pellet resuspended in staining media consisting of phosphate buffered saline, $\mathrm{pH} 7.4$, containing 3\% Fetal Clone III (Hyclone, Logan, UT) and $0.1 \%$ sodium azide as a wash step. After this wash, the cell pellet was resuspended in $500 \mu \mathrm{l}$ of staining media containing $1 \%$ fresh paraformaldehyde. Samples were stored at $4 \mathrm{C}$ in the dark for no more than 48 hours before flow cytometry analysis.

\section{Flow cytometry, FACS, and antibodies}

Evaluation of nucleated cells from whole blood specimens was performed by standard flow cytometry on a FACScalibur (Becton Dickinson, Franklin Lakes, NJ) instrument with identical set up parameters between samples, using appropriate primary or fluorochrome conjugated monoclonal antibodies against cell surface markers to CD3, CD14, CD20, CD56, CD66acde, CD80, CD83 CD86, appropriate isotype control, and secondary antibodies (Caltag Laboratories, Burlingame, CA), CD11C, (BD Biosciences, San Diego, CA), and MHC II (Ancell Bayport, MN) as noted in Table 2. Flow cytometry data was analyzed using FlowJo software (Tree Star, Ashland, OR).

There is no consensus for the most appropriate gating strategy for circulating DC enumeration. Classic quadrant gates [56-58], more restricted MHC class II high expressing gates [59,60], and even more inclusive gates [61] have been employed for DC enumeration with and without restriction of the examined cellular subset by side scatter $\&$ forward scatter gating, complicating direct comparison of results from different groups. Thus, we evaluated three different gating profiles in two color analyses of lineage negative, MHC class II positive putative DC populations. We set standard quadrant gates from isotype control samples with less than $0.2 \%$ background in all positive gates, "Gate A". DCs generally have high-level expression of MHC class II, thus we also examined various levels of higher MHC class II expression within this gate. In our experience with whole blood staining and analyses, discrete populations with different levels of MHC class II expression are rarely observed. Thus, these gates were arbitrarily set at $\geq 10^{2} \log$ FL-2 fluorescence, "Gate B", or $\geq 10^{3}$ log FL-2 fluorescence, "Gate C", see Figure 1. Although there are certainly other gating strategies, these three strategies represent a range of restriction for the level of $\mathrm{MHC}$ class II expression in the lineage negative, MHC II positive, putative DC population.

Cells for photomicrography were obtained by fluorescent activated cell sorting (FACS) collecting MHC class II positive, lineage negative and lineage positive populations using "Gate B" settings. These samples were used to generate cytospin preparations. Cytospin preparations were air dried and stained with standard Wright-Giemsa. Photomicrographs were obtained using a cooled color CCD camera (Diagnostic Instruments, Sterling Heights, MI).

\section{Statistical methods}

The two-tailed Wilcoxon signed rank tests were used to test for significant differences between comparisons conducted within individual sample sets, e.g., normal or patient sets. The two-tailed Mann-Whitney tests were used to test for significant differences in intergroup comparisons. Pearson's R was calculated to assess the degree of correlation between replicate analyses from given samples as a measure of reproducibility in this whole blood analytical strategy. Figures were generated using Graph Pad Prism (Graph Pad Software, San Diego CA) and Microsoft Excel (Microsoft Corp., Redmond, WA) software programs with statistical analyses performed using SAS software (SAS Institute Inc., Cary NC).

\section{Results \\ DC enumeration by CDI4 and CD66 lineage cocktails in the absence of GM-CSF}

It is widely believed that the proportion of the circulating leukocyte pool that constitutes the circulating dendritic cell population is a small percentage. We evaluated the effect of alternate gating strategies on the number of enumerated DCs from whole blood samples: Gate A represents the classic quadrant gate, Gate B and Gate C employ increasing restrictions on high level MHC class II expression in the lineage negative population, Figure 1 . The boundaries for Gates B \& C were arbitrarily set at $>10^{2}$ and $>10^{3}$ on the $\log$ FL-2 fluorescence scale within Gate A, respectively. The isotype control background for these gate settings were $0.09 \%, 0.00 \%, 0.00 \%$, respectively. Enumeration of putative DCs, in the respective gates, yielded values of; $2.6 \%, 1.17 \%$, and $0.54 \%$, using the CD14 containing lineage cocktail and using the CD66acde containing lineage cocktail; 4.65\%, 4.15\%, $1.03 \%$. The absence of discrete populations of cells with different levels of MHC class II expression and the arbitrary nature of setting these alternate gates accentuate the difficulties of comparing data between groups in the absence of detailed gating strategy descriptions.

The basis for considering alternative DC enumeration flow cytometry strategies is the potential for incorrect classification of leukocytes, either as DCs or as non-DCs, par- 
Table 2: Antibodies employed in these studies

\begin{tabular}{|c|c|c|c|c|c|}
\hline Antigen & Fluorochrome & Clone & Isotype & Vendor & Volume \\
\hline CD3 & FITC & S4.I & $\lg G 2 a$ & Caltag & $5 \mathrm{ul}$ \\
\hline CDIIC & PE/Cy5 & B-ly6 & $\operatorname{lgGI}$ & BD Biosciences & $10 \mathrm{ul}$ \\
\hline CDI4 & FITC & TüK4 & $\lg G 2 a$ & Caltag & $5 \mathrm{ul}$ \\
\hline CD20 & FITC & $\mathrm{HI} 47$ & $\lg G 3$ & Caltag & $5 \mathrm{ul}$ \\
\hline CD56 & FITC & MEM- 188 & $\lg G 2 a$ & Caltag & $5 \mathrm{ul}$ \\
\hline CD66acde & FITC & CLB-gran/10 & $|g G|$ & Caltag & $5 \mathrm{ul}$ \\
\hline CD80 & Tricolor & MEM-233 & $\lg G \mid$ & Caltag & $5 \mathrm{ul}$ \\
\hline CD83 & Tricolor & $\mathrm{HBI} 5 \mathrm{e}$ & $|g G|$ & Caltag & $5 \mathrm{ul}$ \\
\hline CD86 & Tricolor & BU63 & $|g G|$ & Caltag & $5 \mathrm{ul}$ \\
\hline MHC II & $\mathrm{PE}$ & TDR3I.I & $|g G|$ & Ancell & $4 \mathrm{ul}$ \\
\hline
\end{tabular}

ticularly in the setting of GM-CSF administration. To gain insight into the extent of this potential error, we examined several specimens with three-color, flow cytometric analysis to determine the distribution of cells expressing CD11c, CD14, CD80, CD83, or CD86, in the various populations delineated by lineage cocktail and MHC class II reactivity. Table 3 summarizes a representative set of analyses from a subject sample after receiving GM-CSF. The vast majority of the CD14 expressing population resided in the lineage positive, MHC class II positive cell subset for both lineage cocktails, $82 \%$ and $76 \%$, respectively. Increasing restriction on high MHC class II expression led to an enrichment of the percentage of cells expressing CD14 for both cocktails, although to a greater extent in the CD66acde cocktail. This accounted for the increase in identified putative DC in the CD66acde cocktail analyses vs. the CD14 cocktail analyses. CD11c expression has been associated with DCs in the presence of MHC class II expression. Slightly less than half of the MHC class II positive, CD11c positive cells resided in the lineage positive population for samples analyzed with the CD14 lineage cocktail, while this percentage was much higher in the CD66acde lineage cocktail analysis. Increasing restriction on high MHC class II expression led to an enrichment of the percentage of cells residing within the gated population expressing either $\mathrm{CD} 11 \mathrm{c}$ or $\mathrm{CD} 14$ with the CD66acde cocktail, whereas in the CD14 cocktail analyses the proportion of CD11c positive cells varied little across the three gates. Interestingly, approximately identical proportions of CD66acde lineage negative, MHC class II positive putative DCs enumerated by the CD66acde cocktail expressed CD14 or CD11c, supporting their appropriate classification as circulating DCs. Although the proportion of nucleated cells expressing CD80, CD83, or CD86 resided solely in the MHC class II positive pool, there were slightly higher proportions identified in the lineage negative, MHC class II positive populations from the CD66acde cocktail analyses. Nearly identical trends to those depicted in Table 3 were seen in samples from subjects not receiving GM-CSF. Together, these data suggest that monocytes are classified similarly by both cocktails and support the under classification of DCs by analyses using the CD14 cocktail.

Given the fact that immature DCs can have low level CD14 expression, we predicted that even in the absence of GM-CSF administration the alternate cocktail would yield a higher proportion of circulating leukocytes identified as DCs. Thus, we evaluated 18 samples from both normal donors and pre-chemotherapy baseline samples from subjects that would go on to receive GM-CSF. The DC populations were initially enumerated using the criteria of lineage negative, MHC class II positive defined by isotype control quadrant gating at $\leq 0.2 \%$ thresholds, Gate A. There was a trend toward the CD66acde lineage cocktail identifying a larger population of putative DCs, although it did not reach statistical significance, Figure 2. The overlapping box and whisker plots from all samples suggests that these two cocktails identify comparable numbers of circulating DCs when employed in a commonly accepted gating strategy, Gate $\mathrm{A}$, in the absence of the biological adjuvant GM-CSF.

\section{Alternate gating strategies with the CDI4 lineage cocktail impart greater variability in enumerated DCs than with the CD66 lineage cocktail}

The three gating strategies for each lineage cocktail were applied to the normal donor samples, Figure 3, panels A \& B, and baseline patient samples, Figure 3, panels C \& D, sets described above. The proportion of circulating leukocytes identified as DCs decreased with restriction to higher level MHC class II expression, Gates B \& C. Within each sample, the identified DC population varied to a greater extent, relative to the employed gating strategy, using the $\mathrm{CD} 14$ containing lineage negative cocktail relative to the CD66 containing lineage negative cocktail. In the setting of the arbitrarily set MHC class II high gates, the number of DCs enumerated in analyses using the CD66 lineage were, as predicted, significantly higher than the population identified by identical analyses using the CD14 lineage cocktail, in the normal sample set $\mathrm{p}=0.0156$ and $\mathrm{p}=$ 0.0781 for Gate $\mathrm{B}$, Figure 3E, and Gate $\mathrm{C}$, Figure 3F, 
Table 3: Expression of select markers on populations categorized by lineage cocktail reactivity and MHC class II expression. This table lists the percentage of nucleated cells residing in each designated gate for each of the two lineage (Lin) cocktails. The first data column, "Total", represents the total percentage of cells within the designated gates described in the far left hand column. Subsequent data columns denote the percentage of cells residing within the designated gate expressing the designated cell surface molecule designated in the top row. Numbers in parentheses represent the percentage molecule expressing cells in the sample; the "ungated" value represents the total percentage.

\begin{tabular}{|c|c|c|c|c|c|c|}
\hline \multirow{2}{*}{$\begin{array}{l}\text { Lineage cocktail \& } \\
\text { gate }\end{array}$} & \multicolumn{6}{|c|}{ Percentage of cells in designated FL-I Fl-2 gate (portion of ungated marker + population) } \\
\hline & Total & $\mathrm{CDIIc}+$ & $\mathrm{CDI} 4+$ & $\mathrm{CD} 80+$ & $\mathrm{CD} 83+$ & $\mathrm{CD} 86+$ \\
\hline \multicolumn{7}{|l|}{ CDI4 cocktail } \\
\hline Ungated & & $(25)$ & $(11.4)$ & (3.9) & (3.4) & $(5.3)$ \\
\hline Lin - MHC II - & 50.2 & $2.9(1.4)$ & $2.5(1.3)$ & $0(0)$ & $0(0)$ & $0(0)$ \\
\hline Lin + MHC II - & 13.5 & $0.6(0.1)$ & $2.0(0.3)$ & $0(0)$ & $0(0)$ & $0(0)$ \\
\hline $\mathrm{Lin}+\mathrm{MHC} \| \mathrm{I}+$ & 12.9 & $82.7(10.6)$ & $72.0(9.3)$ & $30.5(3.9)$ & $25.6(3.3)$ & $39.1(5.0)$ \\
\hline Lin - MHC II + & 23.4 & $52.8(12.3)$ & $2.5(0.6)$ & $0.04(0.01)$ & $0.4(0.1)$ & $0.9(0.3)$ \\
\hline Gate "B" & 6.9 & $67.9(4.7)$ & $4.6(0.3)$ & $0.1(0.01)$ & $0(0)$ & $0.15(0.01)$ \\
\hline Gate "C" & 0.11 & $66.7(0.1)$ & $18.2(0.02)$ & $10(0.01)$ & $0(0)$ & $0.06(0)$ \\
\hline \multicolumn{7}{|l|}{ CD66 cocktail } \\
\hline Ungated & & $(23.8)$ & $(12.3)$ & (3.1) & $(2.8)$ & $(5.8)$ \\
\hline Lin - MHC II- & 12.9 & $1.7(0.2)$ & $0.2(0.02)$ & $0.08(0.01)$ & $0(0)$ & $0(0)$ \\
\hline $\mathrm{Lin}+\mathrm{MHC}$ II - & 52 & $3(1.6)$ & I.I $(0.6)$ & $0(0)$ & $0.02(0.01)$ & $0(0)$ \\
\hline $\mathrm{Lin}+\mathrm{MHC} \| \mathrm{I}+$ & 28.7 & $66.8(19.2)$ & $32.5(9.3)$ & $10.4(3.0)$ & $9.9(2.8)$ & $18.3(5.3)$ \\
\hline Lin - MHC II + & 6.4 & $44(2.8)$ & $36.9(2.4)$ & $1.58(0.1)$ & $1.25(0.01)$ & $8.5(0.5)$ \\
\hline Gate "B" & 3.8 & $68.8(2.6)$ & $61.3(2.3)$ & $2.7(0.1)$ & $1.9(0.01)$ & I4.4(0.5) \\
\hline Gate "C" & 1.4 & $95(1.3)$ & $89.9(1.3)$ & $7(0.1)$ & $5.7(0.01)$ & $27.4(0.4)$ \\
\hline
\end{tabular}

respectively and in the experimental sample set $\mathrm{p}<0.001$ and $\mathrm{p}=0.001$ for Gate B, Figure 3E, and Gate C, Figure 3F, respectively. This result is not unexpected given the low level CD14 expression on immature DCs and the prediction that a large proportion of circulating DCs are likely to have the immature phenotype.

\section{Longitudinal change in putative DC populations in the setting of repeated GM-CSF dosage}

Individuals receiving dose-dense chemotherapy supported by the growth factor GM-CSF were evaluated prechemotherapy and after 10 days of daily GM-CSF administration. The administration of GM-CSF was generally accompanied by a longitudinal increase in number of circulating nucleated cells identified as DCs, Figure 4. The degree of increase was variable as was the baseline proportion of DCs, though the CD66acde containing cocktail analyses generally identified a larger DC population than the CD14 containing lineage cocktail. Although with restriction to higher levels of MHC class II expression in the CD14 cocktail analyses, there was a dramatic shift in the longitudinal profile; from all but three individuals having an increase in circulating DCs after GM-CSF administration in Gate A, to only three having an increase identified using Gate C, Figure 4, panel C. This inconsistency was not seen across the three gates for analyses using the CD66acde lineage cocktail. It is reassuring that in general, longitudinal changes were concordant between comparable analyses using the different cocktails. Given the wide range of GM-CSF effects and the widely held belief that circulating DCs represent a small percentage of circulating nucleated cells, the substantial populations of putative DCs identified by employing Gate $A_{,}>10 \%$ of circulating nucleated cells in some individuals, seem likely to be an over estimation of the DC population. It is difficult to reconcile the near global longitudinal decrease in circulating DCs using the CD14 lineage cocktail and Gate C, Figure 4, panel C, with the biological activity of GM-CSF and the general agreement between the other analyses, Figure 4, panels A, B, D, E, \& F. The discordance between longitudinal analyses using the CD14 and CD66acde lineage cocktails, accentuate the difficulties inherent in these analyses in the setting of repetitive GMCSF administration.

\section{Reproducibility of DC enumeration}

As noted above, all whole blood samples were evaluated prior to PBMC isolation and/or cryopreservation. Thus, to assess reproducibility of determinations using either lineage cocktail, replicate aliquots from individual samples were stained and analyzed. Scatter plots of these replicate determinations are depicted in Figure 5. Data derived from CD14 containing lineage cocktail determinations employing all three gates, Figure 5, panel A, and from CD66acde containing lineage cocktail determinations, Figure 5, panel B, reveal a very high level of concordance with the best fit lines as follows: $y=1.036 x$ (Pearson's $\mathrm{R}=$ 0.9968 ) and $y=0.9417 x$ (Pearson's $R=0.9740$ ), respec- 


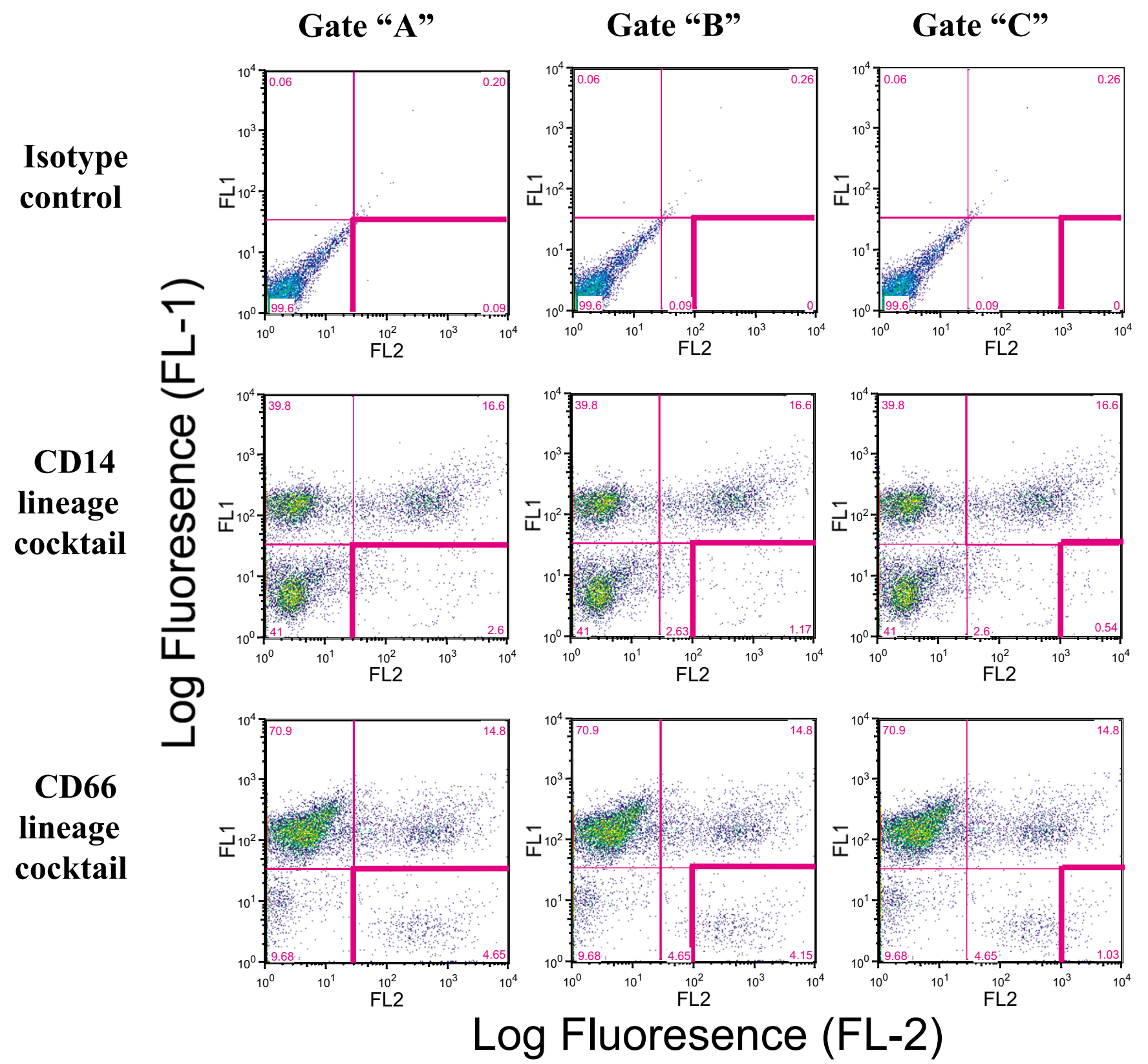

Figure I

Alternate "gates" for flow cytometric enumeration of circulating dendritic cells. Representative dot plots of two color flow cytometric evaluations from one of the six anonymous "normal" donor samples. All plots depict log fluorescence of FL-I (Lineage - FITC) on the "Y axis" and FL-2 on the "X" axis (MHC II - PE) with collection of a minimum of 50,000 events. The left hand column depicts "Gate A", classic quadrant gates. The middle column depicts the least restrictive of the arbitrarily set $\mathrm{MHC}$ class II high expression subset "Gate B". The right hand column depicts the most restrictive MHC class II high expressing population, "Gate C". The first row represents isotype control analyses and gate settings that have $0.09 \%, 0.00 \%$, $0.00 \% \geq$ background, respectively.

tively. Restricting the data set to Gate $\mathrm{C}$, the most stringent criteria for identifying putative DCs, results in comparable levels of concordance for the analyses using the CD14 lineage cocktail, $y=1.012 x$ (Pearson's $R=0.9367$ ), Figure 5, panel $\mathrm{C}$, and for the analyses using the CD66acde lineage cocktail, $\mathrm{y}=0.9463 \mathrm{x}$ (Pearson's $\mathrm{R}=0.9703$ ), Figure 5, panel $\mathrm{D}$. These data support the comparable reproducibility of analyses using either of these two lineage cocktails. 


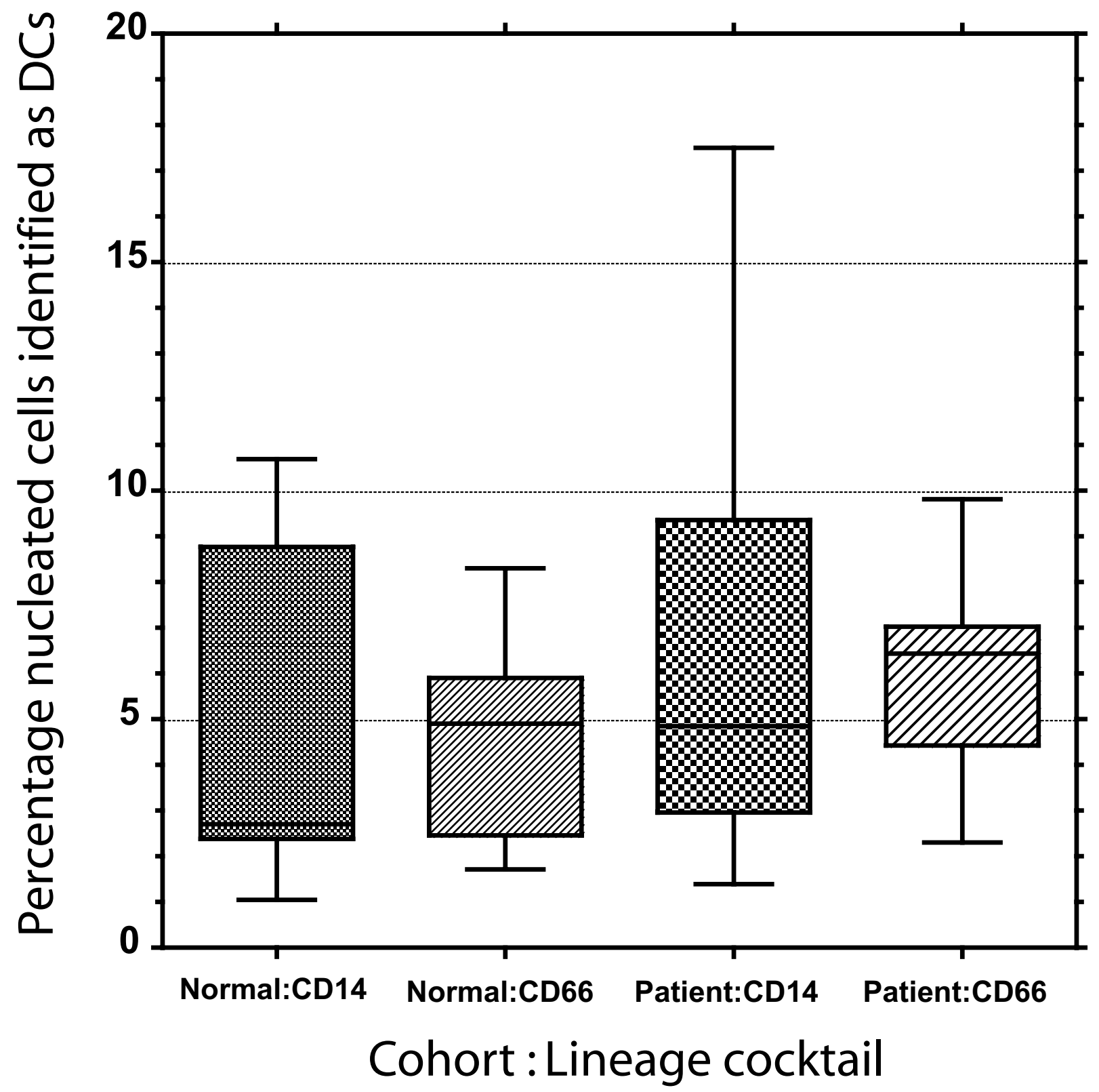

Figure 2

Comparison of CDI4 and CD66acde containing lineage cocktails for flow cytometry DC enumeration in the absence of repeated GM-CSF administration. Each set of percent DC determinations for the designated samples and lineage cocktail formulation are depicted as box and whisker plots depicting the median, bold line within the box, the bounds of the $25^{\text {th }}$ and $75^{\text {th }}$ percentile, the box, and the data set range, the whisker.

The CD66 lineage cocktail identifies a more homogenous population in the setting of repeated GM-CSF administration

MHC class II positive, lineage negative and lineage posi- tive populations obtained by standard fluorescent activated cell sorting (FACS) using Gate B were used for generating cytospin preparations from three post-GM-CSF patient samples. The limited numbers of cells present in 
Table 4:

\begin{tabular}{|c|c|}
\hline Antibody cocktails & Complicating factors \& potential drawbacks \\
\hline $\begin{array}{l}\left.\text { Lin I (BD Biosciences }{ }^{\circledR}\right) C D 3, C D / 4, C D / 6, C D / 9, C D 20, C D 56 \text { negative: } \\
\text { MHC class II positive. }\end{array}$ & $\begin{array}{l}\text { Low-level expression of CDI4 by "immature" DCs or pDCI }[2,3] \\
\text { Expression of CDI } 6 \text { by a subset of DCs }[3,39,40]\end{array}$ \\
\hline CD / 4, CD / 6 negative: $M H C$ class II, CD33 positive $[56,57]$ & $\begin{array}{l}\text { Low-level expression of CDI4 by "immature" DCs or pDCI }[2,3] \\
\text { Expression of CDI } 6 \text { by a subset of DCs }[3,39,40] \\
\text { Expression pattern of CD33 [62] }\end{array}$ \\
\hline \multicolumn{2}{|l|}{ Single Antibodies } \\
\hline BDCAI, BDCA3 (Miltenyi Biotech ${ }^{\circledR}$ ) & $\begin{array}{l}\text { Identifies a limited subsets of myeloid DCs, CDIc positive subset } \\
\text { (BDCAI) or CDI4I expressing subset (BDCA3) }[3,63]\end{array}$ \\
\hline CMRF clones $[3,64]$ & Identify limited subsets of circulating DCs $[3,64]$ \\
\hline
\end{tabular}

the most restricted gate, Gate $\mathrm{C}$, precluded collection and morphologic analysis of this population from these whole blood stained specimens, even in the setting of repeated GM-CSF administration. Representative photomicrographs from cytospins obtained from one sample are shown in Figure 6. Lineage negative, MHC class II positive populations isolated using the CD14 containing cocktail, Figure 6, panels A \& B, and using the CD66acde containing cocktail, Figure 6 , panels $C \& D$, reveal that the lineage negative, MHC class II positive, putative DC populations isolated with the CD14 cocktail constitutes a pleiomorphic population including granulocytes and immature myeloid cells, best seen at higher power $(400 \times$ original magnification) Figure 6, panel $B$. In contrast, the CD66acde containing lineage negative, MHC class II positive population is more homogenous and has cells with the morphology of immature DCs, Figure 6, panel D.

\section{Discussion}

Various strategies to modulate elements of the DC compartment are being developed and tested. Rigorous methods for evaluating the impact of these strategies on the DC compartment are critical for efficient development and evaluation of individual strategies and for gaining mechanistic understandings of various immunomodulatory strategies. Methods for enumerating DCs should take into account our evolving understanding of the complexity of the DC compartment and the biology of putative immunomodulatory biological adjuvants.

The optimal flow cytometry strategy for enumerating DCs is not known. This is a direct consequence of the absence of a single defining cell surface marker and the phenotypic pleiomorphism of the DC compartment. All of the published and commercially available strategies have potential drawbacks, Table 4; however, different methods may be more applicable in some situations than others. Examination and careful characterization of DC subsets by multi-channel flow cytometry will facilitate increased understanding of the complicated biology of DCs. The alternative cocktail described herein is as compatible as the existing lineage cocktails, with such DC1 subset evaluations.

In pursuing our objective of developing an alternative strategy to provide enumeration of the broader circulating myeloid DC pool than reported lineage cocktails that would be applicable to whole blood flow cytometry analysis and retain the ability to evaluate functional capacity, we investigated several potential substitute cell surface antigens that are not expressed on monocytes. CD66 proved to be the most attractive candidate marker due to its expression on granulocytes, NK cells, lymphocytes, and macrophages and absence of reported expression on DCs [48-55]. The report of reactivity in macrophages and macrophage-like myelomonocytic cell lines raised concerns for as yet unrecognized expression on myeloid DCs. Our data and recent reports that DCs do not express CD66 $[65,66]$, however, do not justify this concern. The low level expression of CD66 family members on the more immature compartments of myelocyte development could complicate the use of this alternative cocktail in the evaluation of bone marrow or enriched progenitor cell preparations. We evaluated the two commercially available antibodies; anti-CD66acde, clone CLB-gran/10 (Caltag) and anti-CD66abce, clone Kat4c (Dako) and found both to yield similar if not identical results (data not shown).

Our analyses using both the standard CD14 and the CD66 containing lineage cocktails to enumerate DCs in normal donors and cancer patients prior to receiving cytotoxic chemotherapy and GM-CSF reveal a slightly higher DC percentage of circulating DCs in nucleated leukocytes than has generally been reported, particularly in Gates A and B. Our data is comparable to reports evaluating DC populations in cord blood. The arbitrary restriction to a high MHC class II expressing population brings our results more in line with preceding reports. Although use of the CD14 lineage cocktail sporadically yielded a suggestion of a discrete population with higher MHC class II expression, such as in Figure 1, careful examination failed 

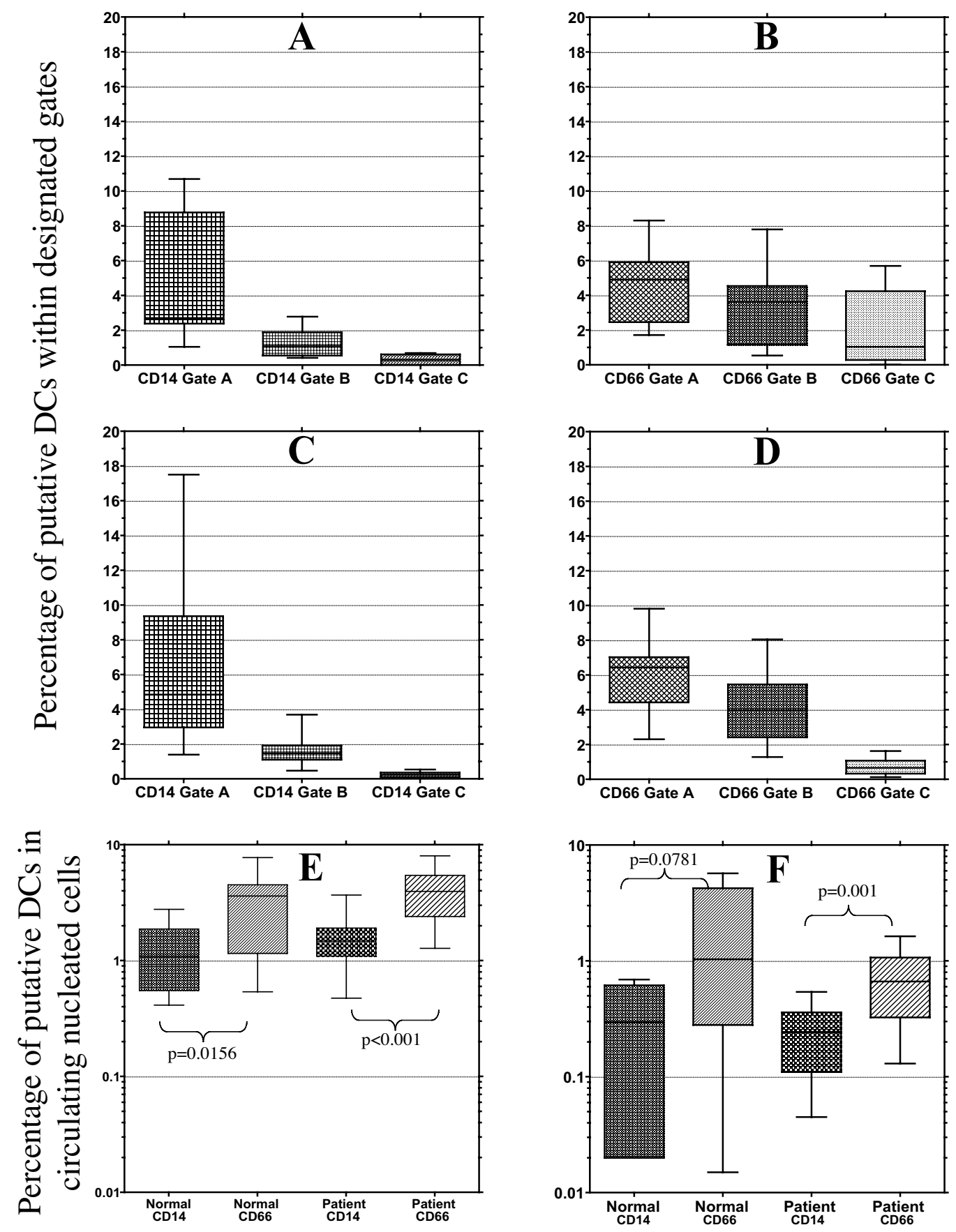

Figure 3

Effect of alternate gating strategies on DC enumeration by lineage cocktail. Box and whisker plots of compiled data for percentage DCs in normal and patient samples using the three alternate gating strategies. Normal samples evaluated using the CDI 4 containing lineage cocktail are depicted in Panel A and evaluated using the CD66 containing lineage cocktail depicted in Panel B, using the designated gates on the " $X$ " axis. Patient samples evaluated using the CDI 4 containing lineage cocktail are depicted in Panel $C$ and evaluated using the CD66 containing lineage cocktail depicted in Panel D, using the designated gates on the "X" axis. Within each sample set the differences between analyses using each of the three gates are statistically significant at $p$ values $\leq 0.03$ I 2. Direct comparison of enumerated values for putative DCs in both "Normal and "Patient" baseline samples as detected using each lineage cocktail with Gate B, Panel E, and with Gate C, Panel F, reveals consistent and statistically significant differences, as noted, between determinations using the different cocktails. 


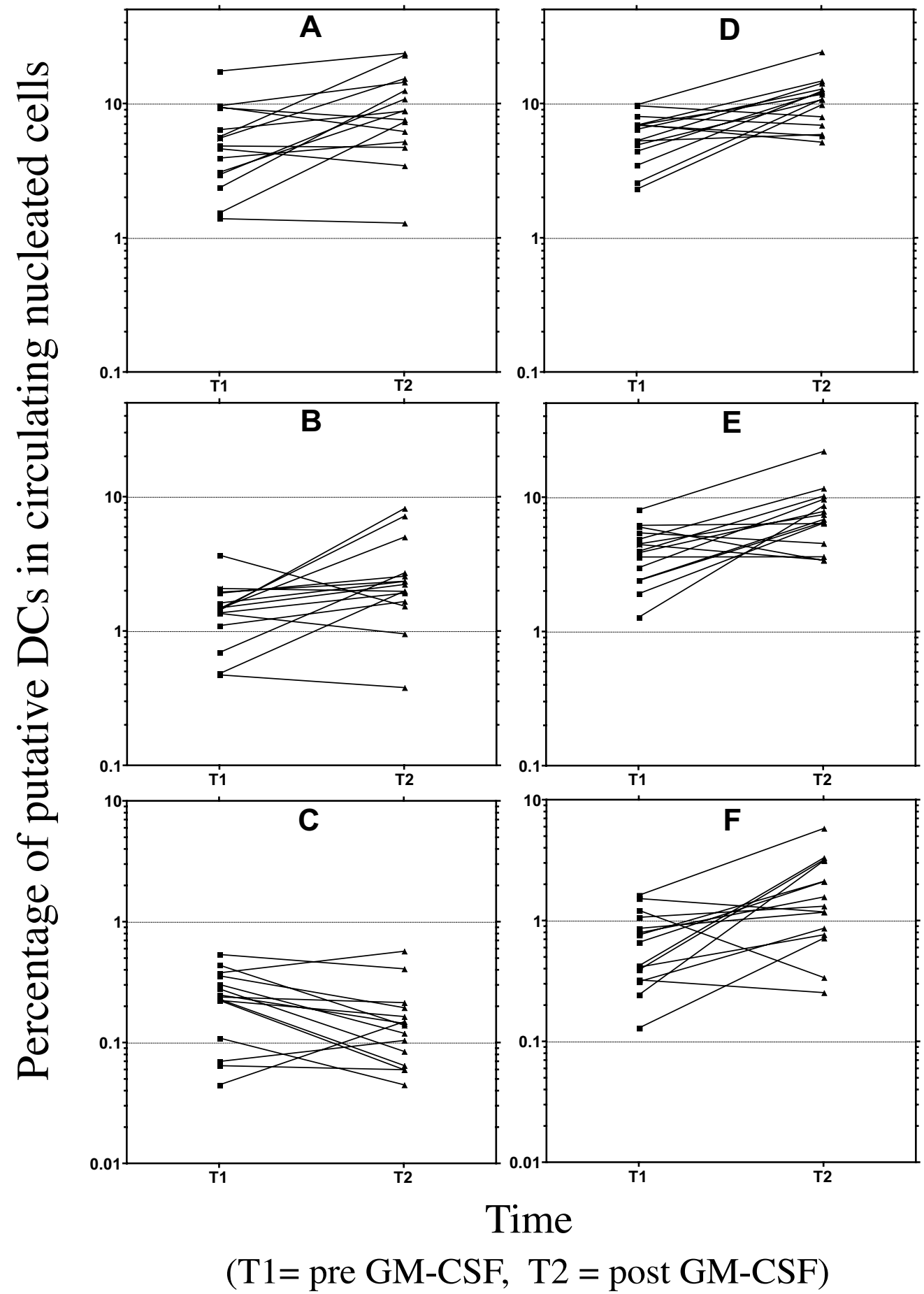

\section{Figure 4}

Longitudinal changes in circulating DCs in the setting of daily GM-CSF. Individual plots of data derived from patient samples using the various gating strategies and the two lineage cocktails. Each line depicts the longitudinal change in the percentage of nucleated cells identified as DCs in individual subject's samples at baseline (TI) and after I0 days of daily GM-CSF (T2). The left hand column represents determinations using the CDI4 containing lineage cocktail and the right hand column the determinations using the CD66 containing cocktail. Panels A \& D depict Gate A determinations. Panels B \& E depict the Gate $B$ gated population. Panels $C$ \& F depict the Gate $C$ determination, with a change to log scale to accommodate the range of values. 

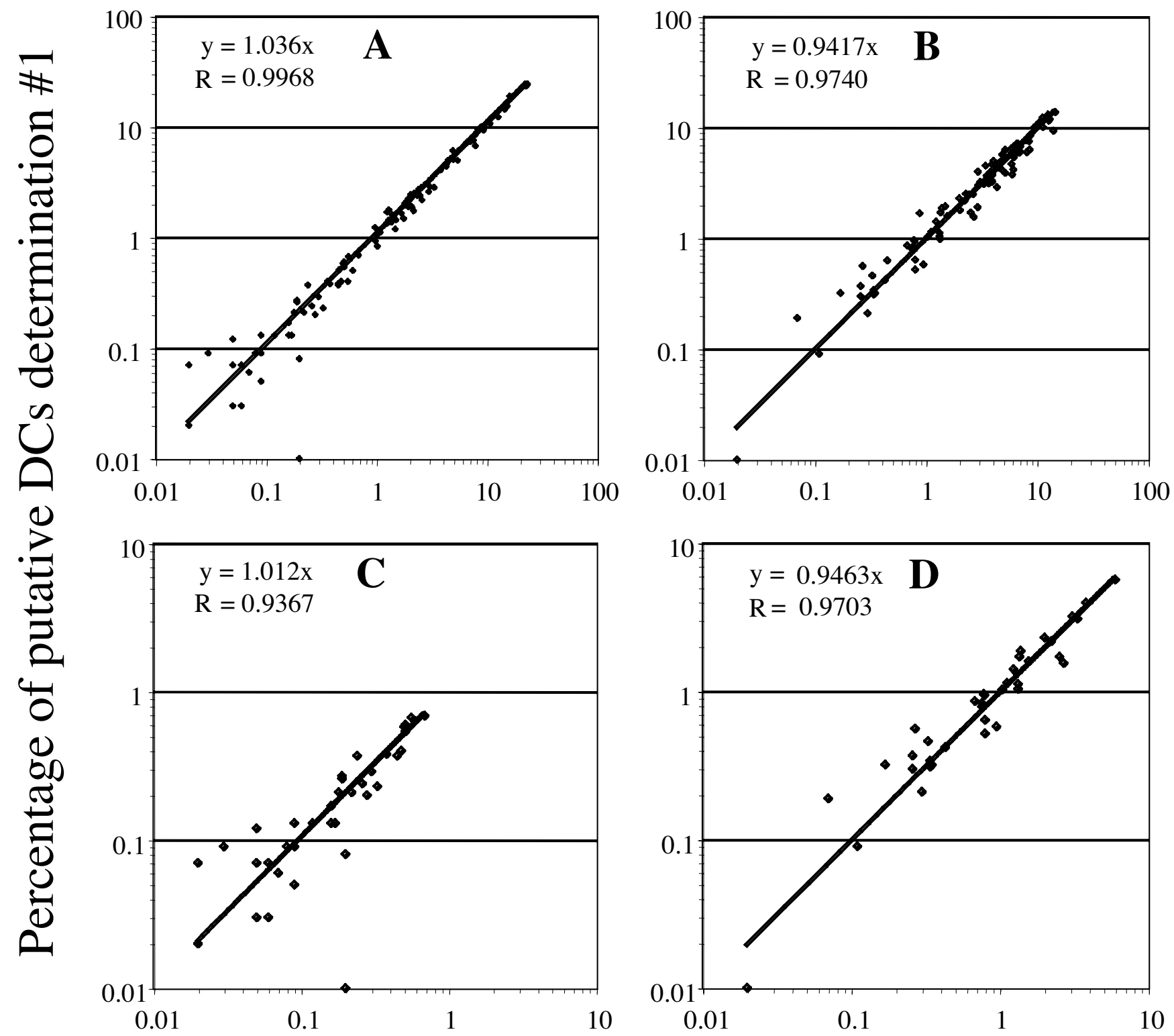

\section{Percentage of putative DCs determination \#2}

Figure 5

Reproducibility of whole blood flow cytometric enumeration of DCs. Scatter plots of independent duplicate analyses of each individual fresh whole blood sample are presented for the CDI4 containing lineage cocktail, Panel A, and the CD66acde containing lineage cocktail, Panel $B$. There is a high degree of concordance between replicate analyses including data from all gating strategies, Panel A, (CDI4 containing cocktail) with the best fit line constrained by passing through the origin and Pearson's $R$ being $y=1.036 x R=0.9968$. Panel $B$ depicts the identical data for the CD66acde containing cocktail, $y=$ $0.94 I 7 x R=0.9740$. Data restricted to Gate $C$ yields a similar degree of concordance between replicate analyses with the best fit line constrained by passing through the origin and Pearson's $R$ being $y=1.012 x R=0.9367$ for CDI 4 lineage cocktail analyses, Panel C, and for analyses using the CD66acde containing cocktail being $y=0.9463 \times R=0.9703$, Panel $D$. 


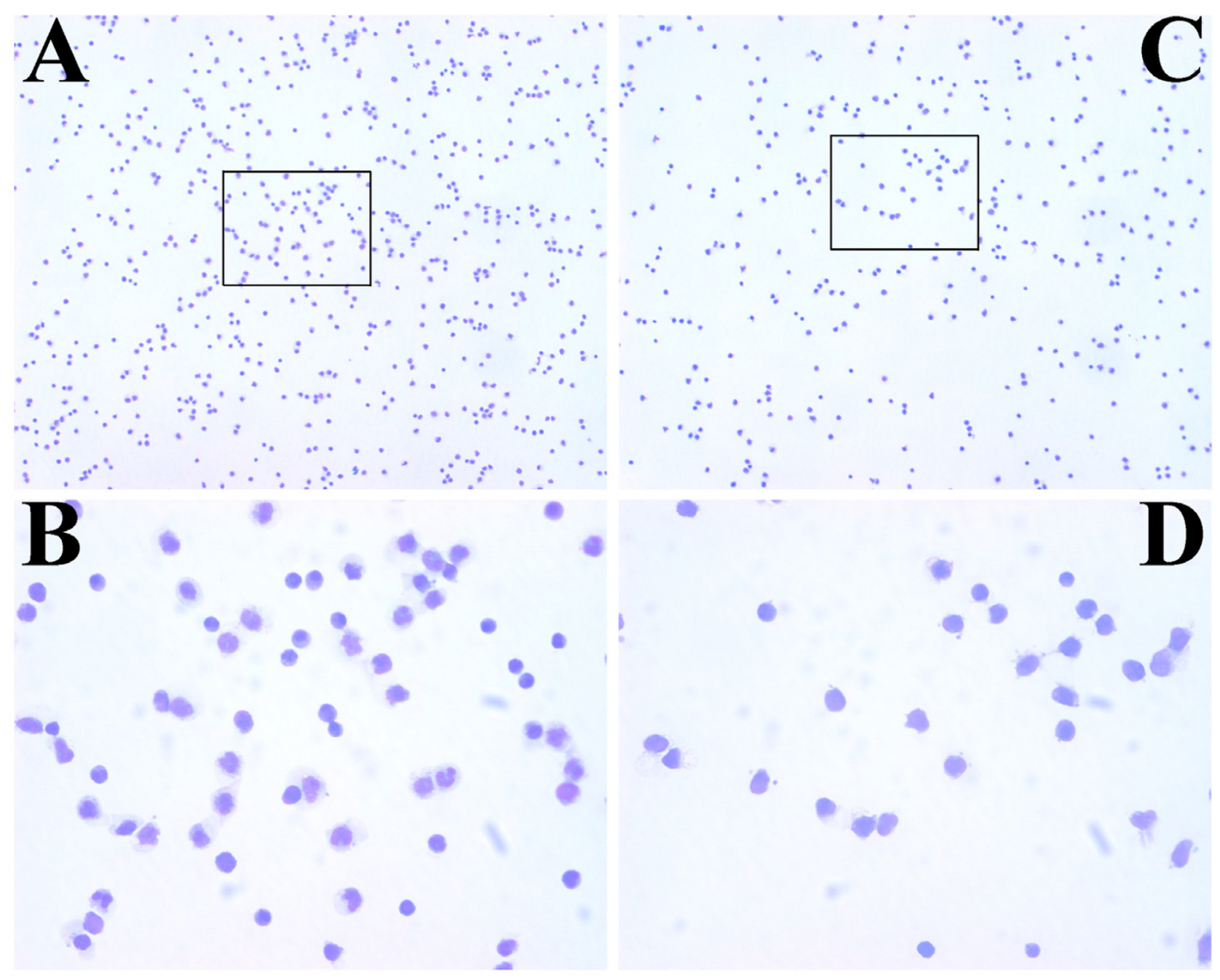

\section{Figure 6}

Photomicrographs of FACS isolated populations. Individual panels depict representative Wright-Geimsa stained cytospin preparations of MHC class II positive, lineage negative or lineage positive populations isolated by FACS using Gate B parameters from samples collected from an individual after ten consecutive days of GM-CSF following cytotoxic chemotherapy. Panels A \& C depict photomicrographs (original magnification 100x) of lineage negative, MHC class II positive populations for CDI4 and CD66acde containing cocktails, respectively. Panels B \& D depict higher magnification (original magnification 400x) of the boxed regions in Panel A \& C, respectively. These data are representative of analyses performed on three separate samples.

to convincingly demonstrate a discrete population. We are concerned that setting arbitrary MHC class II high expression gates imparts a significant potential for bias, diminished reproducibility, and accuracy. Interestingly, recent studies report comparable percentages of circulating DCs $[67,68]$ to those seen with the CD66 alternative cocktail employing Gate A or B. We are reassured by the reproducibility of determinations using both cocktails that is entirely comparable to similar strategies using various cocktails [32,56-58,60,61,69-73], even though some of these studies examined only the "mature", i.e. CD83 positive, circulating DC populations [32] or specific DC sub- sets $[32,56,57,60,61,69-73]$. A similar degree of interpatient variability in longitudinal changes of putative circulating DCs was reported in the study of repetitive daily, $x$ 7d, GM-CSF and concomitant IL-4 administration [60] and in the study of repetitive daily, $x$ 14d, GM-CSF administration [32]. Both lineage cocktails may incorrectly classify activated immature myeloid elements, potentially myeloid suppressor cells [74-76], as putative DCs. It was somewhat surprising that the CD66 containing cocktail yielded group data with less variability across gating strategies and with greater longitudinal concordance, in the setting of daily GM-CSF administration, than the CD14 
containing cocktail. Under normal circumstances CD66 and CD14 are not necessarily co-expressed on human leukocytes [77] however there is evidence for CD66 expression on activated monocytes and macrophages [54,77] suggesting that at least a proportion of CD14 cells also express CD66. Together with our limited data using threecolor flow cytometry analyses of CD14 expression on lineage positive or lineage negative, MHC class II positive populations, suggest that activated monocytes or macrophages are not being routinely classified as DCs in the CD66acde cocktail analyses. It is likely that the error imparted by excluding CD14 expressing immature DCs with the standard cocktail is at least as large as any error due to inclusion of $\mathrm{CD} 14$ positive monocytes in the putative DC population using the CD66acde cocktail. This is supported by the observed cellular morphology of the lineage negative, MHC class II positive population from post GM-CSF samples that is more uniform and, more importantly, representative of DCs and DC precursors as previously reported $[56,78]$ when the CD66 containing lineage cocktail is employed.

\section{Conclusion}

We have demonstrated that substituting an antibody for CD66acde for an antibody recognizing CD14 within a cocktail of antibodies to define lineage negative, MHC class II positive populations, i.e. putative circulating DC populations, yields population sizes of comparable magnitude across different gating strategies in baseline samples from normal donors and cancer patients prior to initiation of cytotoxic chemotherapy and hematopoetic growth factor support. The data derived from use of the alternate CD66 containing cocktail is less subject to changes in gating strategies. This alternate lineage cocktail likely classifies CD14 low, MHC class II positive circulating cells, correctly as putative DCs while classifying the large majority of CD14 positive cells in the lineage positive, non-DC, population. In patients receiving cytotoxic chemotherapy and hematopoetic support with daily GMCSF the longitudinal data obtained with the CD66 containing cocktail is more uniform and concordant across gating strategies than that obtained with the CD14 containing lineage cocktail. Finally, in representative FACS isolated lineage negative, MHC class II positive populations from such patients the putative DC population is more homogenous and representative of DCs. Together, these data support the use of this alternative lineage negative cocktail, particularly in the setting of sustained hematopoetic growth factor, e.g. GM-CSF, use.

\section{Competing interests}

The author(s) declare that they have no competing interests.

\section{Authors' contributions}

KW and KPN performed the analyses and participated in manuscript preparation. RSM is the principle investigator for the clinical trials and as such was primarily responsible for the conception and conduct of the clinical trial that was the source of the patient samples. ELN conceived the study, participated in the design of the clinical trial, and was responsible for conduct of these studies along with preparation of the manuscript. All authors read and approved the manuscript.

\section{Acknowledgements}

We thank members of the clinical research office of the University of California at Irvine, Chao Family Comprehensive Cancer Center and the $\mathrm{UCl}$ GCRC for their invaluable assistance in coordinating this study and conduct of the normal blood donor program, respectively. This work was supported in part by institutional pilot project funds provided under the auspices of the Chao Family Comprehensive Cancer Center and the clinical study was supported by an investigator-initiated pharmaceutical supported research award, UCl 03-70, from Berlex Inc., Montville, NJ, USA.

\section{References}

I. Ridgway D: The first $\mathbf{1 0 0 0}$ dendritic cell vaccinees. Cancer Invest 2003, 2 I :873-886.

2. Shortman K, Liu YJ: Mouse and human dendritic cell subtypes. Nat Rev Immunol 2002, 2:151-161.

3. MacDonald KP, Munster DJ, Clark GJ, Dzionek A, Schmitz J, Hart DN: Characterization of human blood dendritic cell subsets. Blood 2002, 100:4512-4520.

4. Nelson EL, Strobl S, Subleski J, Prieto D, Kopp WC, Nelson PJ: Cycling of human dendritic cell effector phenotypes in response to TNF-alpha: modification of the current 'maturation' paradigm and implications for in vivo immunoregulation. Faseb J 1999, 13:2021-2030.

5. Chang DZ, Lomazow W, Joy Somberg C, Stan R, Perales MA: Granulocyte-macrophage colony stimulating factor: an adjuvant for cancer vaccines. Hematology 2004, 9:207-2I5.

6. Martinez-Moczygemba M, Huston DP: Biology of common beta receptor-signaling cytokines: IL-3, IL-5, and GM-CSF. J Allergy Clin Immunol 2003, I I 2:653-665.

7. Dranoff G: GM-CSF-based cancer vaccines. Immunol Rev 2002, I88: I47-I54.

8. Hamilton JA: GM-CSF in inflammation and autoimmunity. Trends Immunol 2002, 23:403-408.

9. Kusmartsev S, Gabrilovich DI: Immature myeloid cells and cancer-associated immune suppression. Cancer Immunol Immunother 2002, 5 I:293-298.

10. Groves RW, Schmidt-Lucke JA: Recombinant human GM-CSF in the treatment of poorly healing wounds. Adv Skin Wound Care 2000, I3:107-II2.

II. Williams MA, Kelsey SM, Newland AC: GM-CSF and stimulation of monocyte/macrophage function in vivo relevance and in vitro observations. Eur J Cancer 1999, 35(Suppl 3):SI8-22.

12. Baldwin GC: The biology of granulocyte-macrophage colonystimulating factor: effects on hematopoietic and nonhematopoietic cells. Dev Biol 1992, I5 I:352-367.

13. Altomonte M, Fonsatti E, Visintin A, Maio M: Targeted therapy of solid malignancies via HLA class II antigens: a new biotherapeutic approach? Oncogene 2003, 22:6564-6569.

14. Altomonte M, Pucillo C, Maio M: The overlooked "nonclassical" functions of major histocompatibility complex (MHC) class II antigens in immune and nonimmune cells. J Cell Physiol I999, I 79:25|-256.

15. Suzumura Y, Ohasi M: Immunoelectron microscopic localization of HLA-DR antigen on mast cells and vessels in normal and tuberculin-reactive skin. Am J Dermatopathol I991, I3:568-574. 
16. Xie ML, Wu YG: GM-CSF and IFN-gamma-induced expression of human leucocyte antigen class II molecules on basophils of umbilical cord blood. Acta Pharmacol Sin 2002, 23:645-648.

17. Jordan JH, Walchshofer S, Jurecka W, Mosberger I, Sperr WR, Wolff K, Chott A, Buhring HJ, Lechner K, Horny HP, Valent P: Immunohistochemical properties of bone marrow mast cells in systemic mastocytosis: evidence for expression of CD2, CD I I 7 I Kit, and bcl-x(L). Hum Pathol 200I, 32:545-552.

18. Dimitriadou V, Mecheri S, Koutsilieris M, Fraser W, Al-Daccak R Mourad W: Expression of functional major histocompatibility complex class II molecules on HMC-I human mast cells. J Leukoc Biol 1998, 64:791-799.

19. Saikh KU, Kissner T, Ulrich RG: Regulation of HLA-DR and costimulatory molecule expression on natural killer $\mathrm{T}$ cells by granulocyte-macrophage colony-stimulating factor. Immunology 2002, 106:363-372.

20. Reinisch W, Lichtenberger C, Steger G, Tillinger W, Scheiner O, Gangl A, Maurer D, Willheim M: Donor dependent, interferongamma induced HLA-DR expression on human neutrophils in vivo. Clin Exp Immunol 2003, 133:476-484.

21. Radsak M, lking-Konert C, Stegmaier S, Andrassy K, Hansch GM: Polymorphonuclear neutrophils as accessory cells for T-cell activation: major histocompatibility complex class II restricted antigen-dependent induction of T-cell proliferation. Immunology 2000, 101:521-530.

22. Ottonello L, Epstein AL, Dapino P, Barbera P, Morone P, Dallegri F: Monoclonal Lym-I antibody-dependent cytolysis by neutrophils exposed to granulocyte-macrophage colony-stimulating factor: intervention of FcgammaRII (CD32), CDI IbCD 18 integrins, and CD66b glycoproteins. Blood 1999, 93:3505-35II.

23. Smith WB, Guida L, Sun Q, Korpelainen El, van den Heuvel C, Gillis D, Hawrylowicz CM, Vadas MA, Lopez AF: Neutrophils activated by granulocyte-macrophage colony-stimulating factor express receptors for interleukin-3 which mediate class II expression. Blood 1995, 86:3938-3944.

24. Mudzinski SP, Christian TP, Guo TL, Cirenza E, Hazlett KR, Gosselin EJ: Expression of HLA-DR (major histocompatibility complex class II) on neutrophils from patients treated with granulocyte-macrophage colony-stimulating factor for mobilization of stem cells. Blood 1995, 86:2452-2453.

25. Gosselin E], Wardwell K, Rigby WF, Guyre PM: Induction of MHC class II on human polymorphonuclear neutrophils by granulocyte/macrophage colony-stimulating factor, IFN-gamma, and IL-3. J Immunol I993, I 5 I: | 482- I 490

26. Grabstein K, Mochizuki D, Kronheim S, Price V, Cosman D, Urdal D, Gillis S, Conlon P: Regulation of antibody production in vitro by granulocyte-macrophage colony stimulating factor. J Mol Cell Immunol 1986, 2:199-207.

27. Szabolcs P, Avigan D, Gezelter S, Ciocon DH, Moore MA, Steinman RM, Young JW: Dendritic cells and macrophages can mature independently from a human bone marrow-derived, postcolony-forming unit intermediate. Blood 1996, 87:4520-4530.

28. Szabolcs P, Moore MA, Young JW: Expansion of immunostimulatory dendritic cells among the myeloid progeny of human CD34+ bone marrow precursors cultured with c-kit ligand, granulocyte-macrophage colony-stimulating factor, and TNF-alpha. J Immunol I995, 154:585I-586I.

29. Thomassen MJ, Barna BP, Rankin D, Wiedemann HP, Ahmad M: Differential effect of recombinant granulocyte macrophage colony-stimulating factor on human monocytes and alveolar macrophages. Cancer Res 1989, 49:4086-4089.

30. Young JW, Szabolcs P, Moore MA: Identification of dendritic cell colony-forming units among normal human CD34+ bone marrow progenitors that are expanded by c-kit-ligand and yield pure dendritic cell colonies in the presence of granulocyte/macrophage colony-stimulating factor and tumor necrosis factor alpha. J Exp Med 1995, I82: I III-IIII9.

31. Chachoua A, Oratz R, Hoogmoed R, Caron D, Peace D, Liebes L, Blum RH, Vilcek J: Monocyte activation following systemic administration of granulocyte-macrophage colony-stimulating factor. J Immunother Emphasis Tumor Immunol I 994, I 5:2 I 7-224.

32. Demir G, Klein HO, Tuzuner N: Low dose daily rhGM-CSF application activates monocytes and dendritic cells in vivo. Leuk Res 2003, 27: $1105-1108$.
33. Wing EJ, Magee DM, Whiteside TL, Kaplan SS, Shadduck RK: Recombinant human granulocyte/macrophage colony-stimulating factor enhances monocyte cytotoxicity and secretion of tumor necrosis factor alpha and interferon in cancer patients. Blood 1989, 73:643-646.

34. Caulfield JJ, Hawrylowicz CM, Kemeny DM, Lee TH: GM-CSF increases the ability of cultured macrophages to support autologous CD4+ T-cell proliferation in response to Dermatophagoides pteronyssinus and PPD antigen. Immunology 1997, 92:123-130.

35. Coleman DL, Chodakewitz JA, Bartiss AH, Mellors JW: Granulocyte-macrophage colony-stimulating factor enhances selective effector functions of tissue-derived macrophages. Blood 1988, 72:573-578.

36. Jones TC: The effect of granulocyte-macrophage colony stimulating factor (rGM-CSF) on macrophage function in microbial disease. Med Oncol 1996, I3:141-147.

37. Dong Z, Kumar R, Yang X, Fidler IJ: Macrophage-derived metalloelastase is responsible for the generation of angiostatin in Lewis lung carcinoma. Cell I997, 88:80I-8I0.

38. Kumar R, Dong Z, Fidler IJ: Differential regulation of metalloelastase activity in murine peritoneal macrophages by granulocyte-macrophage colony-stimulating factor and macrophage colony-stimulating factor. J Immunol 1996, I57:5I04-5III.

39. Lindstedt M, Lundberg K, Borrebaeck CA: Gene family clustering identifies functionally associated subsets of human in vivo blood and tonsillar dendritic cells. J Immunol 2005, I 75:4839-4846.

40. Wilkinson R, Kassianos AJ, Swindle P, Hart DN, Radford KJ: Numerical and functional assessment of blood dendritic cells in prostate cancer patients. Prostate 2006, 66: $180-192$.

4I. Rose ML: Role of endothelial cells in allograft rejection. Vasc Med 1997, 2:105-114.

42. Ridgway WM, Fathman CG: The association of MHC with autoimmune diseases: understanding the pathogenesis of autoimmune diabetes. Clin Immunol Immunopathol I998, 86:3-I0.

43. Sundstrom JB, Ansari AA: Comparative study of the role of professional versus semiprofessional or nonprofessional antigen presenting cells in the rejection of vascularized organ allografts. Transpl Immunol 1995, 3:273-289.

44. Beninati W, Derdak S, Dixon PF, Grider DJ, Strollo DC, Hensley RE, Lucey DR: Pulmonary eosinophils express HLA-DR in chronic eosinophilic pneumonia. J Allergy Clin Immunol 1993, 92:442-449.

45. Oberhuber G, Puspok A, Peck-Radosavlevic M, Kutilek M, Lamprecht A, Chott A, Vogelsang H, Stolte M: Aberrant esophageal HLADR expression in a high percentage of patients with Crohn's disease. Am J Surg Pathol 1999, 23:970-976.

46. McDouall RM, Batten P, McCormack A, Yacoub MH, Rose ML: MHC class II expression on human heart microvascular endothelial cells: exquisite sensitivity to interferon-gamma and natural killer cells. Transplantation 1997, 64: I I75-I I 80.

47. Yano N, Endoh M, Nomoto $Y$, Sakai H, Rifai A: Increase of HLADR-positive natural killer cells in peripheral blood from patients with IgA nephropathy. Hum Immunol 1996, 49:64-70.

48. Chen D, lijima H, Nagaishi T, Nakajima A, Russell S, Raychowdhury R, Morales V, Rudd CE, Utku N, Blumberg RS: Carcinoembryonic antigen-related cellular adhesion molecule I isoforms alternatively inhibit and costimulate human $\mathbf{T}$ cell function. J Immunol 2004, I72:3535-3543.

49. Singer BB, Scheffrahn I, Heymann R, Sigmundsson K, Kammerer R, Obrink B: Carcinoembryonic antigen-related cell adhesion molecule $I$ expression and signaling in human, mouse, and rat leukocytes: evidence for replacement of the short cytoplasmic domain isoform by glycosylphosphatidylinositollinked proteins in human leukocytes. J Immunol 2002, 168:5|39-5|46.

50. Kammerer R, Hahn S, Singer BB, Luo JS, von Kleist S: Biliary glycoprotein (CD66a), a cell adhesion molecule of the immunoglobulin superfamily, on human lymphocytes: structure, expression and involvement in T cell activation. Eur J Immunol 1998, 28:3664-3674.

5I. Klein ML, McGhee SA, Baranian J, Stevens L, Hefta SA: Role of nonspecific cross-reacting antigen, a CD66 cluster antigen, in activation of human granulocytes. Infect Immun 1996, 64:4574-4579. 
52. Mawhorter SD, Stephany DA, Ottesen EA, Nutman TB: Identification of surface molecules associated with physiologic activation of eosinophils. Application of whole-blood flow cytometry to eosinophils. J Immunol I996, I 56:485 I-4858.

53. Moller MJ, Kammerer R, Grunert F, von Kleist S: Biliary glycoprotein (BGP) expression on $\mathrm{T}$ cells and on a natural-killer-cell sub-population. Int J Cancer 1996, 65:740-745.

54. Botling J, Oberg F, Nilsson K: CD49f (alpha 6 integrin) and CD66a (BGP) are specifically induced by retinoids during human monocytic differentiation. Leukemia 1995, 9:2034-204I.

55. Watt SM, Sala-Newby G, Hoang T, Gilmore DJ, Grunert F, Nagel G, Murdoch SJ, Tchilian E, Lennox ES, Waldmann H: CD66 identifies a neutrophil-specific epitope within the hematopoietic system that is expressed by members of the carcinoembryonic antigen family of adhesion molecules. Blood I99|, 78:63-74.

56. Upham JW, Lundahl J, Liang H, Denburg JA, O'Byrne PM, Snider DP: Simplified quantitation of myeloid dendritic cells in peripheral blood using flow cytometry. Cytometry 2000, 40:50-59.

57. Ma L, Scheers W, Vandenberghe P: A flow cytometric method for determination of absolute counts of myeloid precursor dendritic cells in peripheral blood. J Immunol Methods 2004, 285:215-22I.

58. Wertheimer AM, Bakke A, Rosen HR: Direct enumeration and functional assessment of circulating dendritic cells in patients with liver disease. Hepatology 2004, 40:335-345.

59. Drohan L, Harding J], Holm B, Cordoba-Tongson E, Dekker CL, Holmes T, Maecker H, Mellins ED: Selective developmental defects of cord blood antigen-presenting cell subsets. Hum Immunol 2004, 65: I356-1369.

60. Kiertscher SM, Gitlitz BJ, Figlin RA, Roth MD: Granulocyte/macrophage-colony stimulating factor and interleukin-4 expand and activate type-I dendritic cells (DCI) when administered in vivo to cancer patients. Int J Cancer 2003, 107:256-26I.

61. Chen W, Chan AS, Dawson AJ, Liang X, Blazar BR, Miller JS: FLT3 ligand administration after hematopoietic cell transplantation increases circulating dendritic cell precursors that can be activated by CpG oligodeoxynucleotides to enhance Tcell and natural killer cell function. Biol Blood Marrow Transplant 2005, II:23-34.

62. Fagnoni FF, Oliviero B, Zibera C, Gibelli N, Lozza L, Vescovini R, Sansoni P, Zambelli A, DaPrada G, Robustelli della Cuna G: Circulating CD33+ large mononuclear cells contain three distinct populations with phenotype of putative antigen-presenting cells including myeloid dendritic cells and CD I 4+ monocytes with their CD 16+ subset. Cytometry 200I, 45: 124-132.

63. Dzionek A, Fuchs A, Schmidt P, Cremer S, Zysk M, Miltenyi S, Buck DW, Schmitz J: BDCA-2, BDCA-3, and BDCA-4: three markers for distinct subsets of dendritic cells in human peripheral blood. J Immunol 2000, 165:6037-6046.

64. Radford KJ, Turtle CJ, Kassianos AJ, Vuckovic S, Gardiner D, Khalil D, Taylor K, Wright S, Gill D, Hart DN: Immunoselection of functional CMRF-56+ blood dendritic cells from multiple myeloma patients for immunotherapy. I Immunother 2005, 28:322-331.

65. Yamagami S, Ebihara N, Usui T, Yokoo S, Amano S: Bone marrowderived cells in normal human corneal stroma. Arch Ophthalmol 2006, 124:62-69.

66. Yamagami S, Yokoo S, Usui T, Yamagami H, Amano S, Ebihara N: Distinct populations of dendritic cells in the normal human donor corneal epithelium. Invest Ophthalmol Vis Sci 2005, 46:4489-4494.

67. Vakkila J, Thomson AW, Hovi L, Vettenranta K, Saarinen-Pihkala UM: Circulating dendritic cell subset levels after allogeneic stem cell transplantation in children correlate with time post transplant and severity of acute graft-versus-host disease. Bone Marrow Transplant 2005, 35:50I-507.

68. Basak SK, Harui A, Stolina M, Sharma S, Mitani K, Dubinett SM, Roth MD: Increased dendritic cell number and function following continuous in vivo infusion of granulocyte macrophage-colony-stimulating factor and interleukin-4. Blood 2002, 99:2869-2879.

69. Ferrari S, Malugani F, Rovati B, Porta C, Riccardi A, Danova M: Flow cytometric analysis of circulating dendritic cell subsets and intracellular cytokine production in advanced breast cancer patients. Oncol Rep 2005, I 4: | |3-120.
70. Longman RS, Talal AH, Jacobson IM, Rice CM, Albert ML: Normal functional capacity in circulating myeloid and plasmacytoid dendritic cells in patients with chronic hepatitis C. J Infect Dis 2005, 1 92:497-503.

7I. Yanagimoto H, Takai S, Satoi S, Toyokawa H, Takahashi K, Terakawa $\mathrm{N}$, Kwon $\mathrm{AH}$, Kamiyama Y: Impaired function of circulating dendritic cells in patients with pancreatic cancer. Clin Immunol 2005, I | 4:52-60.

72. Janik JE, Miller LL, Kopp WC, Taub DD, Dawson H, Stevens D, Kostboth P, Curti BD, Conlon KC, Dunn BK, et al.: Treatment with tumor necrosis factor-alpha and granulocyte-macrophage colony-stimulating factor increases epidermal Langerhans' cell numbers in cancer patients. Clin Immunol 1999, 93:209-22 I.

73. Vuckovic S, Gardiner D, Field K, Chapman GV, Khalil D, Gill D, Marlton P, Taylor K, Wright S, Pinzon-Charry A, et al.: Monitoring dendritic cells in clinical practice using a new whole blood singleplatform TruCOUNT assay. J Immunol Methods 2004, 284:73-87.

74. Rodriguez PC, Ochoa AC: $\mathbf{T}$ cell dysfunction in cancer: Role of myeloid cells and tumor cells regulating amino acid availability and oxidative stress. Semin Cancer Biol 2005.

75. Zea AH, Rodriguez PC, Atkins MB, Hernandez C, Signoretti S, Zabaleta J, McDermott D, Quiceno D, Youmans A, O'Neill A, et al: Arginase-producing myeloid suppressor cells in renal cell carcinoma patients: a mechanism of tumor evasion. Cancer Res 2005, 65:3044-3048.

76. Kusmartsev S, Nagaraj S, Gabrilovich DI: Tumor-associated CD8+ $T$ cell tolerance induced by bone marrow-derived immature myeloid cells. J Immunol 2005, I 75:4583-4592.

77. Hansen I, Meyer K, Hokland P: Flow cytometric identification of myeloid disorders by asynchronous expression of the CDI4 and CD66 antigens. Eur J Haematol 1998, 61:339-346.

78. Miller G, Pillarisetty VG, Shah AB, Lahrs S, Xing Z, DeMatteo RP: Endogenous granulocyte-macrophage colony-stimulating factor overexpression in vivo results in the long-term recruitment of a distinct dendritic cell population with enhanced immunostimulatory function. J Immunol 2002, 169:2875-2885

Publish with Bio Med Central and every scientist can read your work free of charge

"BioMed Central will be the most significant development for disseminating the results of biomedical research in our lifetime. "

Sir Paul Nurse, Cancer Research UK

Your research papers will be:

- available free of charge to the entire biomedical community

- peer reviewed and published immediately upon acceptance

- cited in PubMed and archived on PubMed Central

- yours - you keep the copyright 